\title{
LONG 'TIME STABILITY OF A WROUGHT ALLOY 718 DISK
}

\author{
John F. Radavich \\ School of Materials Engineering \\ Purdue University
}

\begin{abstract}
Many of the gas turbine disks currently in operation have experienced exposures of up to 30,000 hours. Other than the early work of Barker, et al., and more recently that of Brooks and Bridges, very little has been published about the effects of longtime stresses and temperatures on microstructural stability of alloy 718 .

A gas turbine disk of alloy 718 with 28,000 hours of engine service time was used in this study. Structures at the top of the firtree and varying distances from the top were structurally characterized by SEM and TEM techniques. The resultant structures and temperatures were compared to those found in alloy 718 material which had undergone $\mathrm{S} / \mathrm{R}$ tests at $1000^{\circ} \mathrm{F}-1300^{\circ} \mathrm{F}$. It was found that the top of the firtree may have been as high as $1325^{\circ} \mathrm{F}$ while the base of the firtree appeared to have been exposed to $1100^{\circ} \mathrm{F}$. When extensive delta precipitation begins to occur in longtimes, the $\gamma^{\prime}$ phase solutions and $\gamma+$ delta become the stable phases. As found in an earlier study, $\alpha \mathrm{Cr}$ forms at the grain boundaries in longtimes at temperatures as low as $1100^{\circ} \mathrm{F}$.
\end{abstract}

\section{Introduction}

Other than the study by Barker in the early 60 's and more recently that of Brooks and Bridges, little has been published about the effects of long-time exposures on the structural stability of alloy 718 disks. The majority of research on alloy 718 has dealt with phases formed in short times such as during heat treatment. Now many alloy 718 disks have acquired many thousands of hours of operation and their degree of structural response to service temperatures would be important to design and material engineers. Moreover with the advent of component repairs and re-heat treat cycles to extend the life of alloy 718 components, a better understanding of the phases formed under stress and at varying temperatures would be important to predict the useful life of the component.

\section{Procedure}

An alloy 718 gas turbine disk with an engine service life of 28,000 hours and possibly exposed to temperatures up to $1300^{\circ} \mathrm{F}$ was made available for study. Because there exists a temperature gradient from the web to the top of the firtree, various locations needed to be evaluated to fully characterize the resultant structures and the temperatures of exposure. The following areas were selected for examination: top of firtree, $5 \mathrm{~mm}$ from the top (T-5), $10 \mathrm{~mm}$ from the top (T-10), $20 \mathrm{~mm}$ from the top (T-20), and the web. While the microstructural changes occurring in longtimes in these areas would be of interest in themselves, the correlation

\footnotetext{
Superalloy 718 -Metallurgy and Applications Edited by E.A. Loria

The Minerals, Metals \& Materials Society, 1989
} 
of the microstructures to the temperatures of operation would be most useful to materials and design engineers. The only known study which made such correlations of temperature and long-time behavior of structures was the early study of Barker at GE.

In the ensuing 20 years since the early study on long-time behavior was carried out, metallographic techniques and phase relationship understanding have improved. To correlate the results of the early study of Barker with those of the 28,000 disk, the same samples from the earlier study were re-evaluated using the techniques used in the current study. The following $\mathrm{S} / \mathrm{R}$ samples were retrieved from that study and re-prepared for evaluation with the disk samples: as-heat treated, $1000^{\circ} \mathrm{F} / 124 \mathrm{KSI} / 8473 \mathrm{hrs}$., $1100^{\circ} \mathrm{F} / 86 \mathrm{KSI} / 34,000 \mathrm{hrs} ., 1100^{\circ}$ F/94KSI/10,606 hrs., $1200^{\circ} \mathrm{F} / 63 \mathrm{KSI} / 10,333 \mathrm{hrs}$., and $1300^{\circ} \mathrm{F} / 37 \mathrm{KSI} / 6048 \mathrm{hrs}$.

All the samples to be studied by SEM were electropolished in a sulphuric-methanol solution and then electrolytically etched in a solution which resolves the structures present but also selectively etches out the $\alpha \mathrm{Cr}$ precipitation which occurs in the grain boundaries in longtime exposures. Probing of the grain boundary precipitation was also carried out by the EDS X-ray analyzer on the SEM. Samples from the top, T-20, and web locations were also characterized by thin film TEM techniques.

\section{S/R Samples}

\section{Results}

The early heat of alloy 718 material was made about 1960 and used for the S/R study showed areas of banding and the normal matrix $\gamma / \gamma^{\prime \prime}$ structures, but after testing at $1000^{\circ} \mathrm{F}$ for 8473 hours, the $\gamma^{\prime} / \gamma^{\prime \prime}$ precipitation had grown larger, Figure 1 . When the material was tested at $1100^{\circ} \mathrm{F}$ for 10,606 hours, the $\gamma^{\prime} / \gamma^{\prime \prime}$ grew appreciably and with continued exposure time of 34,000 hours, a much larger $\gamma / \gamma^{\prime}$ structure developed, Figure 2 . The beginning of precipitation of an $\alpha \mathrm{Cr}$ phase was detected in the grain boundaries in the 34,000 hour sample. The electrolytic etch used in this study preferentially etched out the $\alpha \mathrm{Cr}$ particles at the grain boundaries.

The S/R sample exposed for 10,333 hours at $1200^{\circ} \mathrm{F}$ showed nucleation and growth of delta plates in the grains boundaries. Associated with the delta plate formation was the appearance of round $\gamma^{\prime}$ precipitation and the absence of $\gamma^{\prime \prime}$ plates, Figure 3. The $\gamma^{\prime}$ plates appeared to be breaking down while the spheroidal $\gamma$ became more plentiful. Larger $\alpha \mathrm{Cr}$ particles were seen at the grain boundaries.

Material tested for 6048 hours at $1300^{\circ} \mathrm{F}$ showed greater growth of the delta phase with more $\gamma^{\prime}$ breakdown and conversion to round $\gamma$ formation, Figure 4 . Higher magnification and higher resolution showed the transition of $\gamma^{\prime \prime}$ to $\gamma^{\prime}$. The $\alpha \mathrm{Cr}$ phase at the grain boundaries continued to grow much larger.

\section{8,000 Hour Disk Samples}

The web microstructures typical of as heat treated condition showed the normal delta phase at the grain boundaries and $\gamma^{\prime} / \gamma^{\prime \prime}$ precipitation in the grains, Figure 5. When the area at the base of the firtree, T-20, was examined, delta plates were starting to nucleate and extend into the grains and very fine $\gamma^{\prime}$ spheres were associated with the delta growth, Figure 6.

In the area $10 \mathrm{~mm}$ from the top of the firtree, T-10, more and larger delta growth was present and larger $\gamma^{\prime}$ spheres were found with the delta plates, Figure 7 . The matrix $\gamma / \gamma^{\prime \prime}$ precipitation had grown much larger and $\alpha \mathrm{Cr}$ was now detected in the grain boundaries. The structure $5 \mathrm{~mm}$ from the firtree top, T-5, shows greater delta growth, larger round $\gamma$ particles, and fewer plates of $\gamma^{\prime}$, Figure 8. The $\alpha \mathrm{Cr}$ phase has become more evident in the grain boundaries where more continuous delta plates were growing.

The top area of the firtree showed more of the same structures seen in the T-5 area, Figure 9. Large amounts of delta phase are present and the transition of $\gamma^{\prime \prime}$ into $\delta$ plates and $\gamma$ particles continues as evidenced in grains still containing the $\gamma^{\prime \prime}$ phase. $\alpha \mathrm{Cr}$ particles in the grain boundaries continue to grow.

TEM selected area electron diffraction studies showed the $\gamma^{\prime} / \gamma^{\prime}$ to be precipitated in the web area and at the T-20 location (base of firtree), but only the $\gamma$ phase was found with the delta plates in those areas near the top of the firtree where only round precipitation was present, Figure 10. 


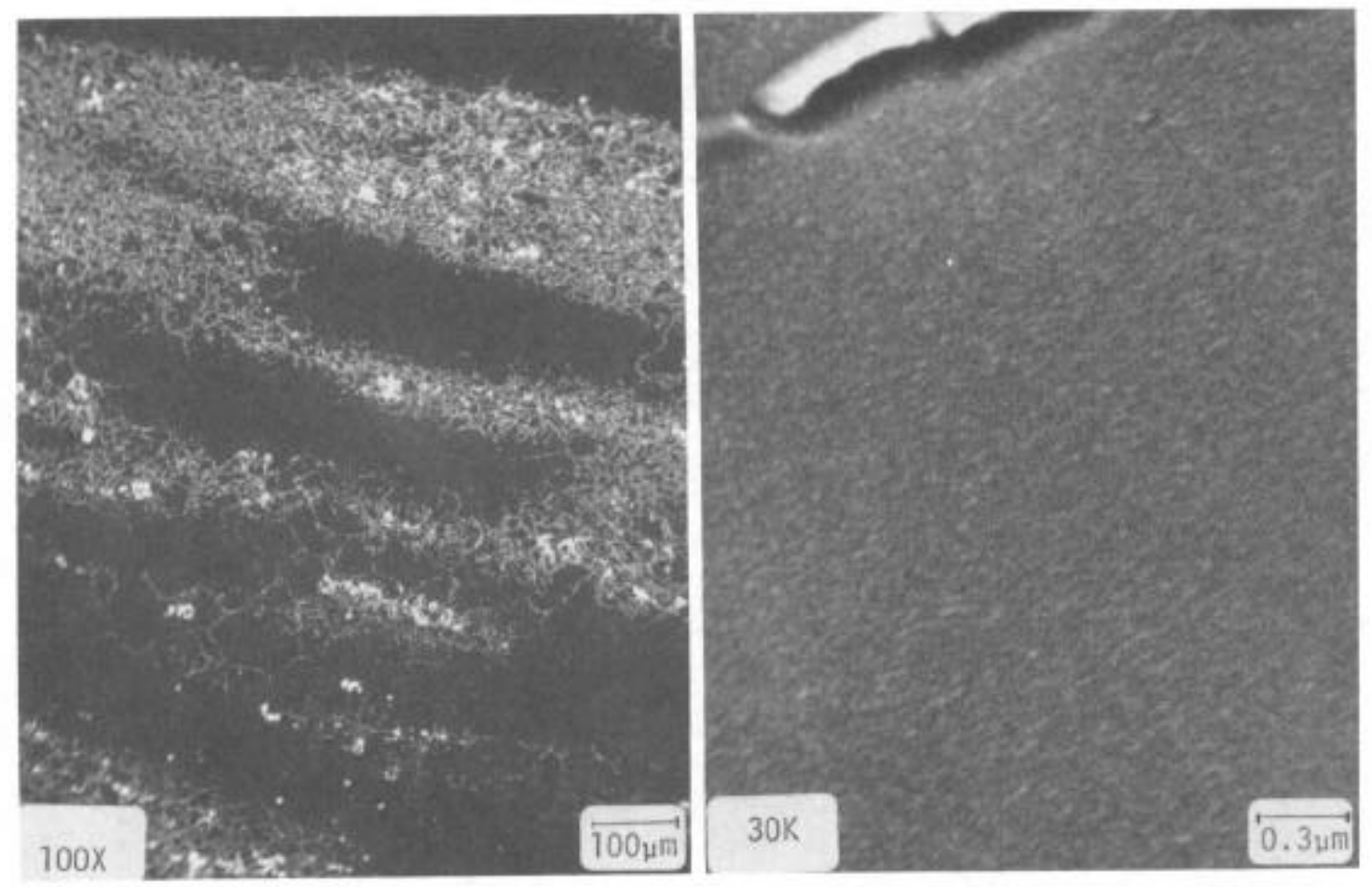

As Heat Treated

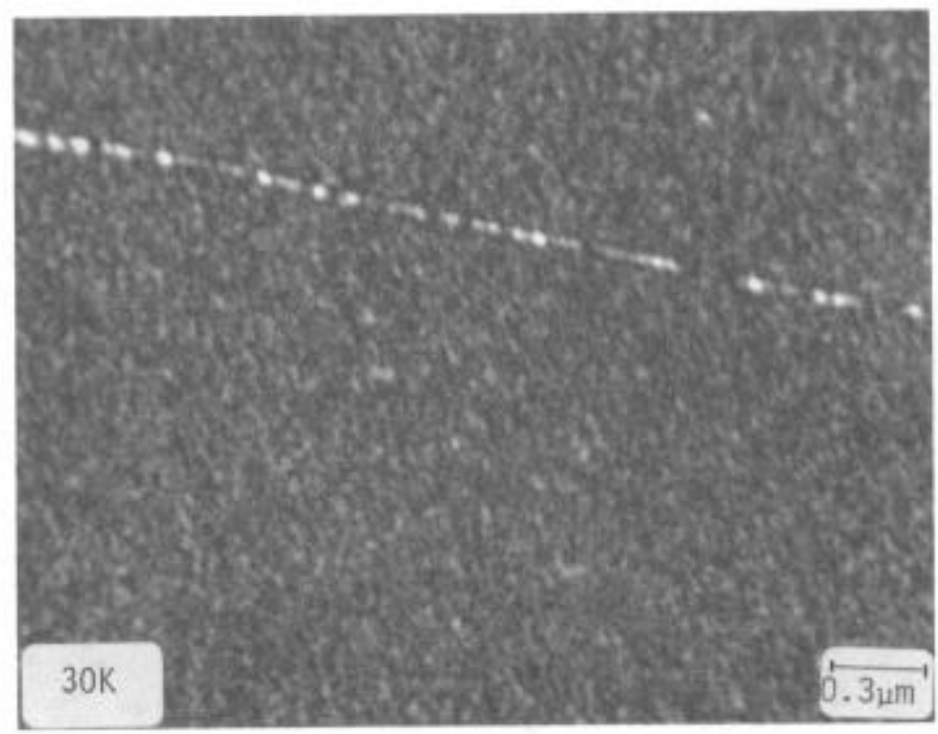

Fig. 1. $1000^{\circ} \mathrm{F} / 124 \mathrm{KSI} / 8473 \mathrm{hr}$. 


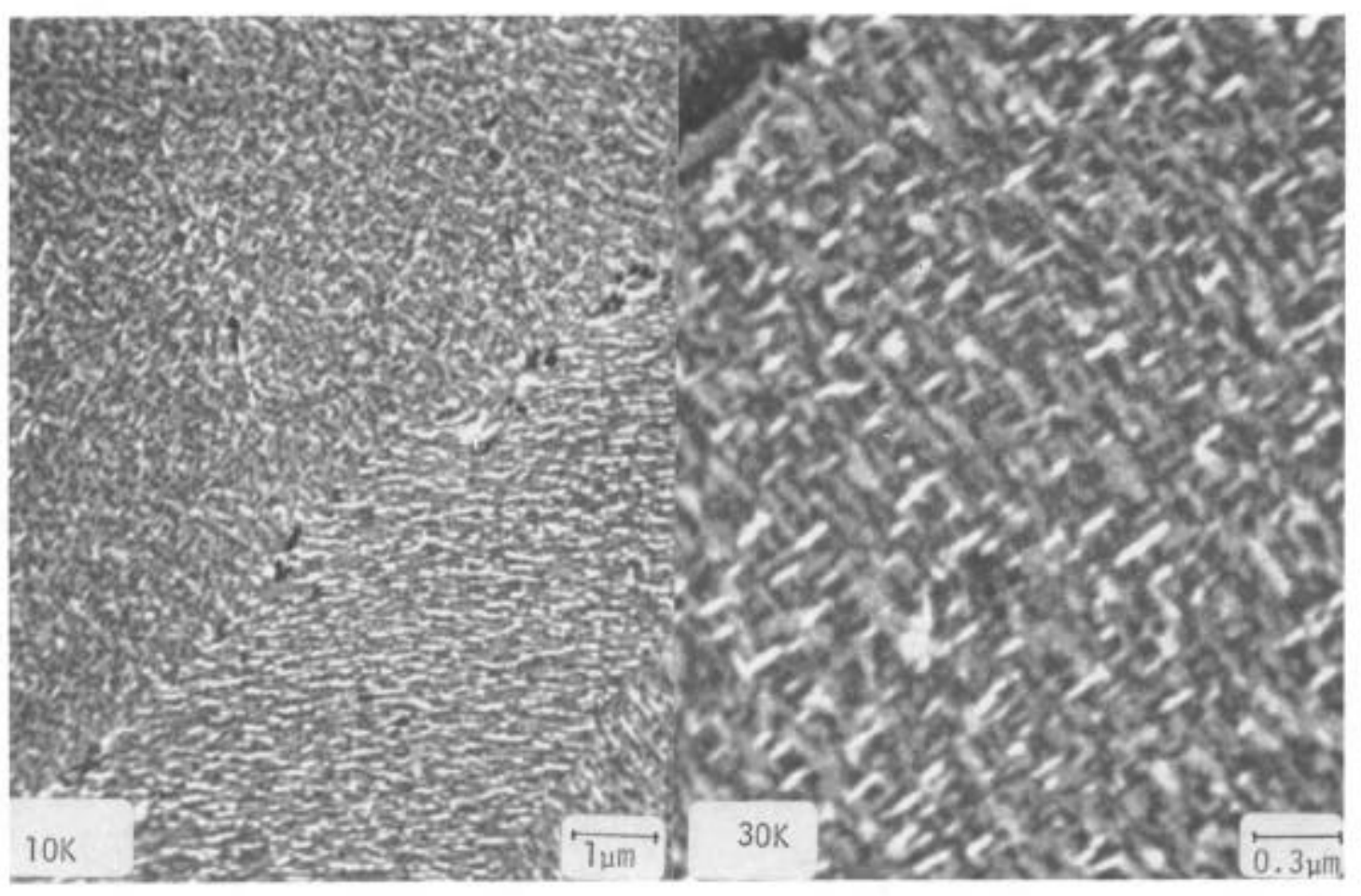

$1100^{\circ} \mathrm{F} / 86 \mathrm{KSI} / 34,000 \mathrm{hr}$.

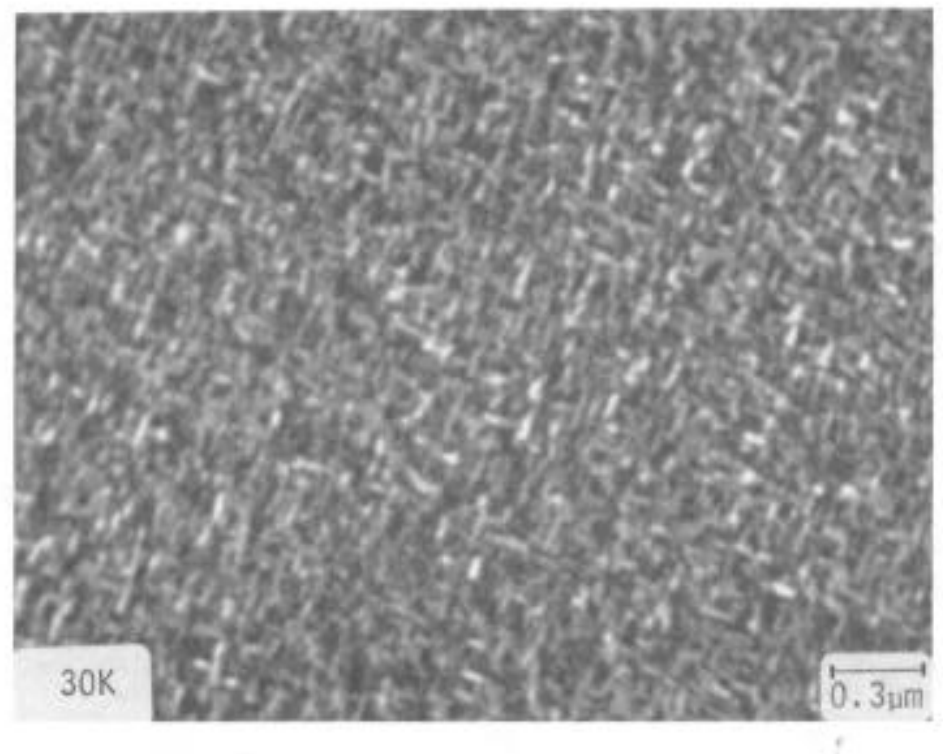

Fig. 2. $1100^{\circ} \mathrm{F} / 94 \mathrm{KSI} / 10,606 \mathrm{hr}$. 

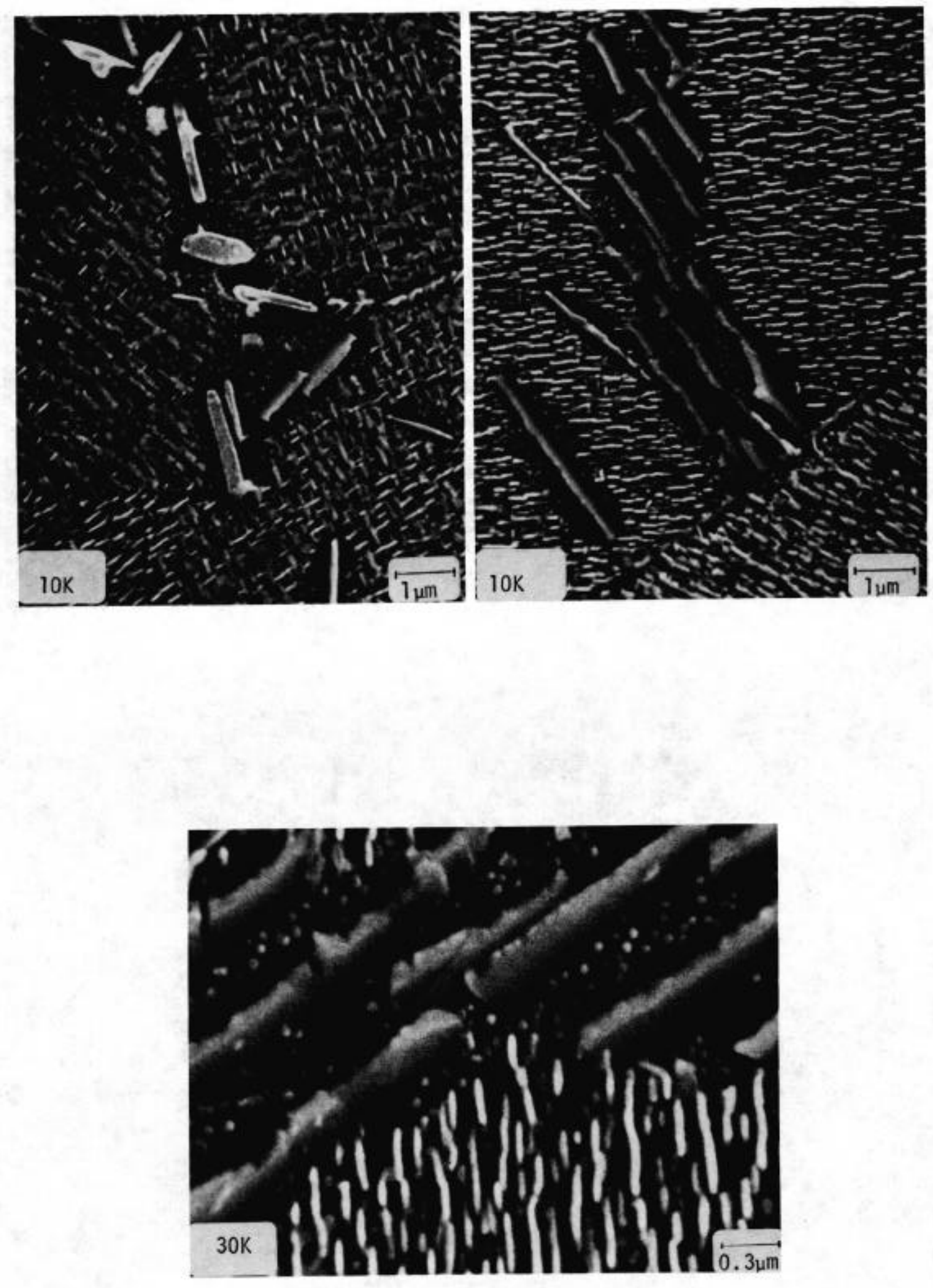

Fig. 3. $1200^{\circ} \mathrm{F} / 63 \mathrm{KSI} / 10,333 \mathrm{hr}$. 

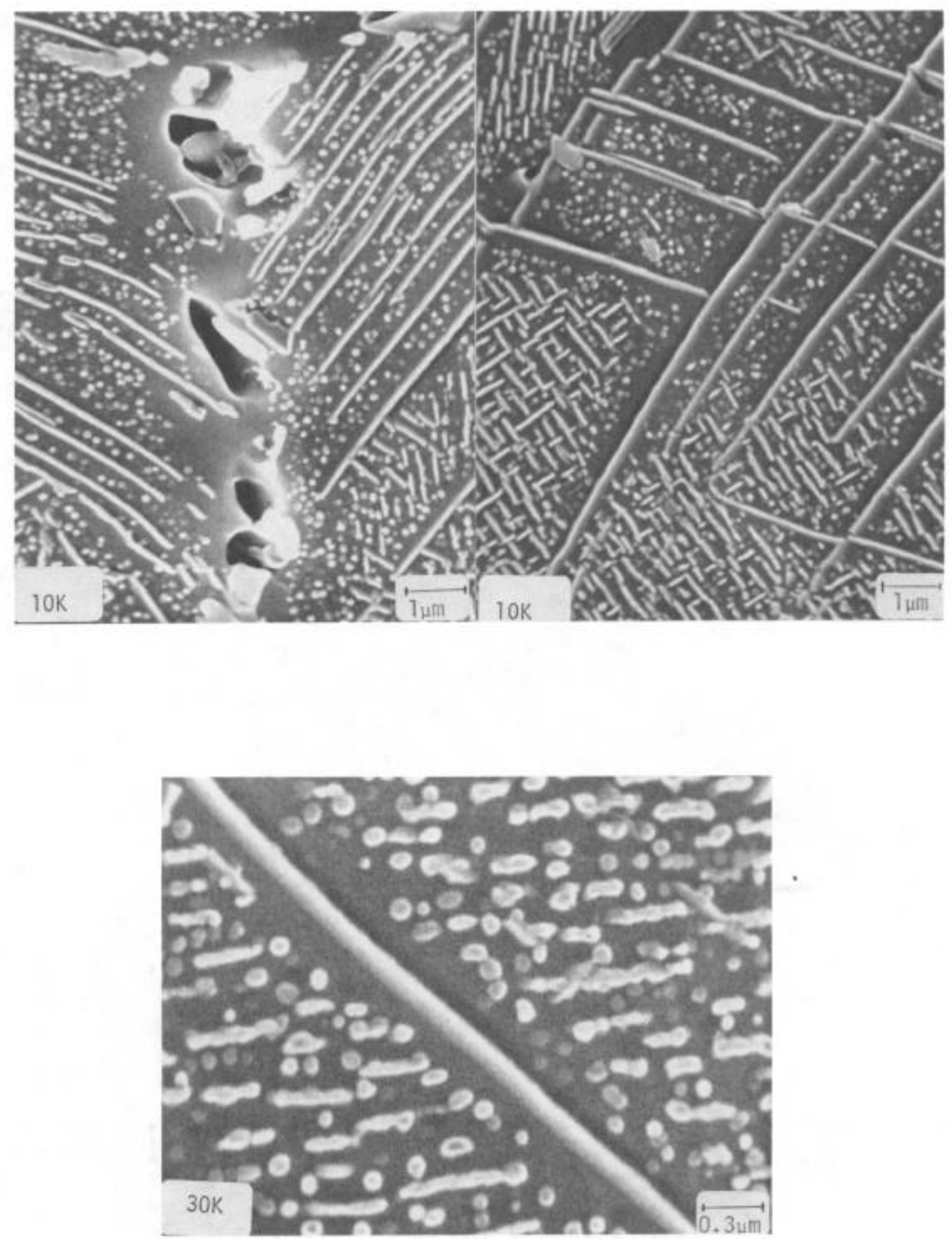

Fig. 4. $1300^{\circ} \mathrm{F} / 37 \mathrm{KSI} / 6048 \mathrm{hr}$. 

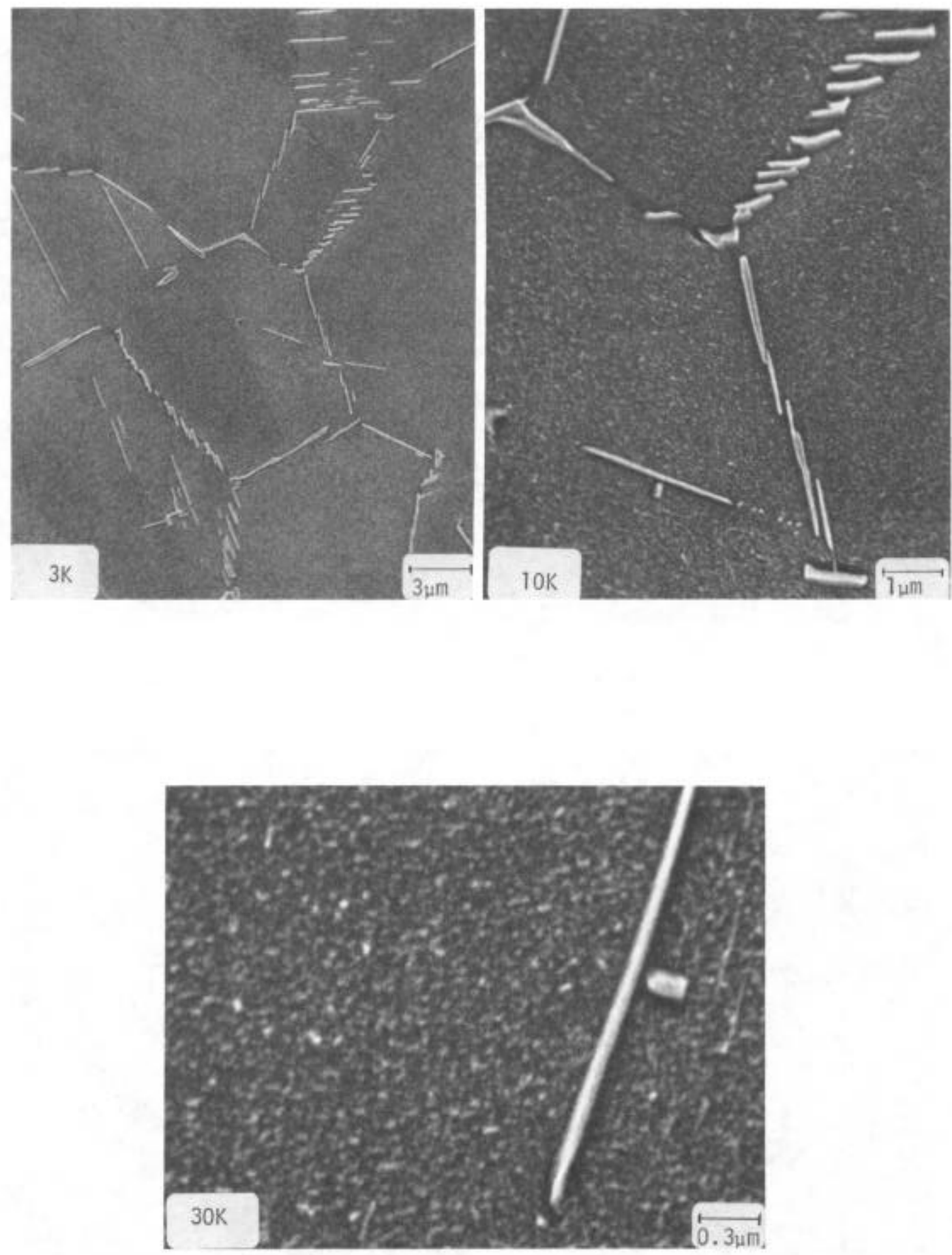

Fig. 5. 28,000 hr. Disk-Web. 

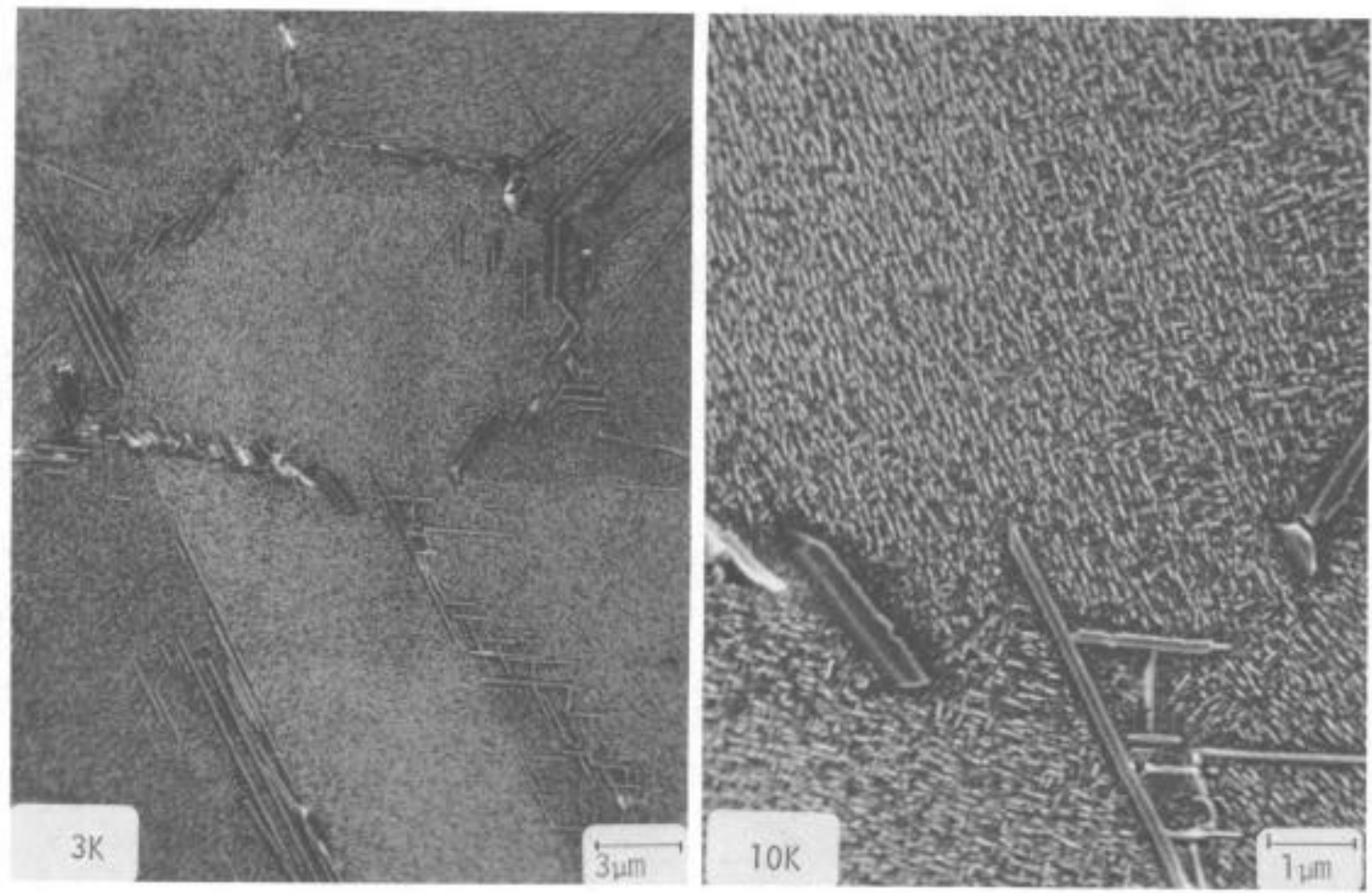

Fig. 6. 28,000 hr. Disk T-20.
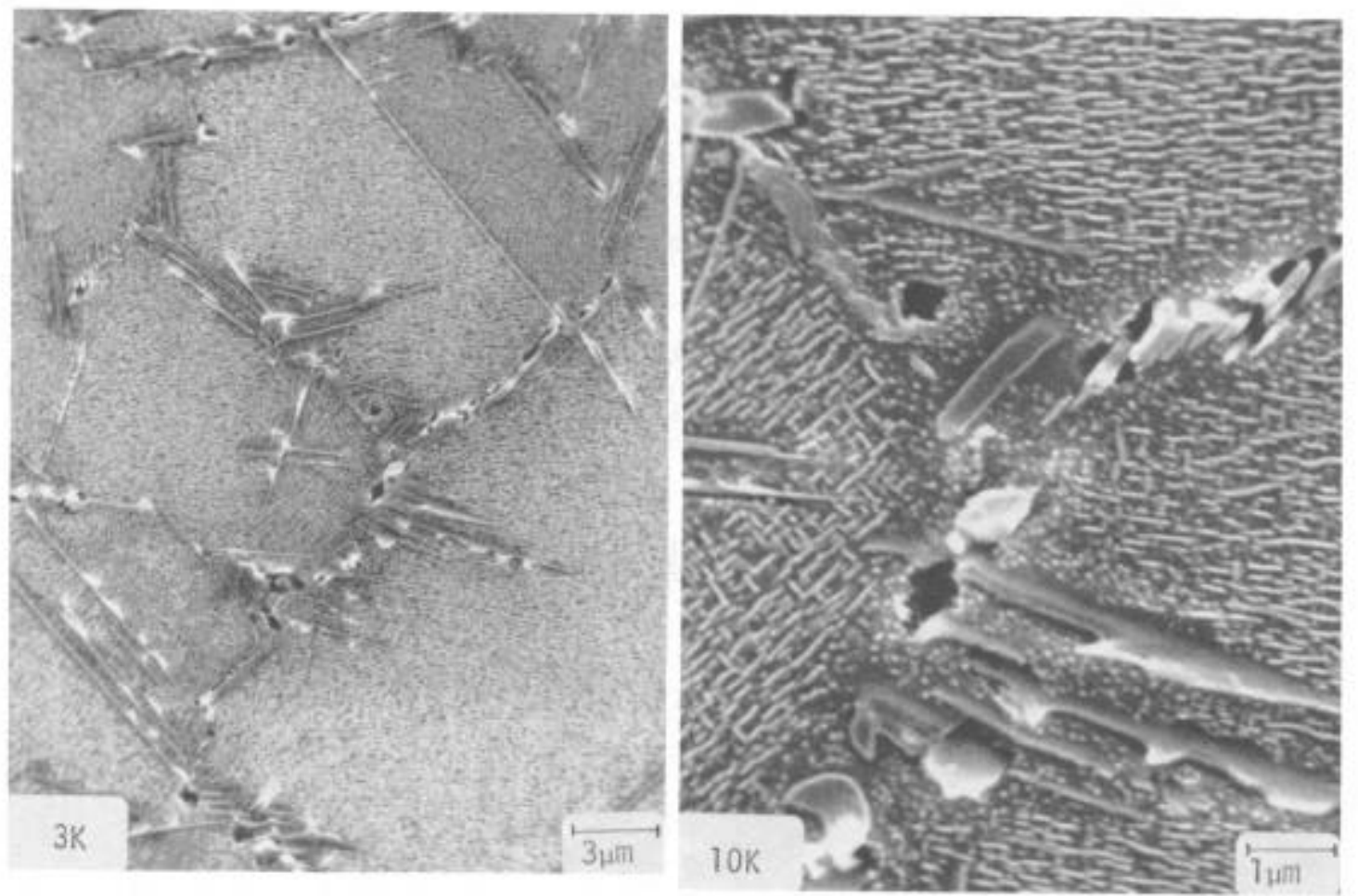

Fig. 7. $28,000 \mathrm{hr}$. Disk T-10. 

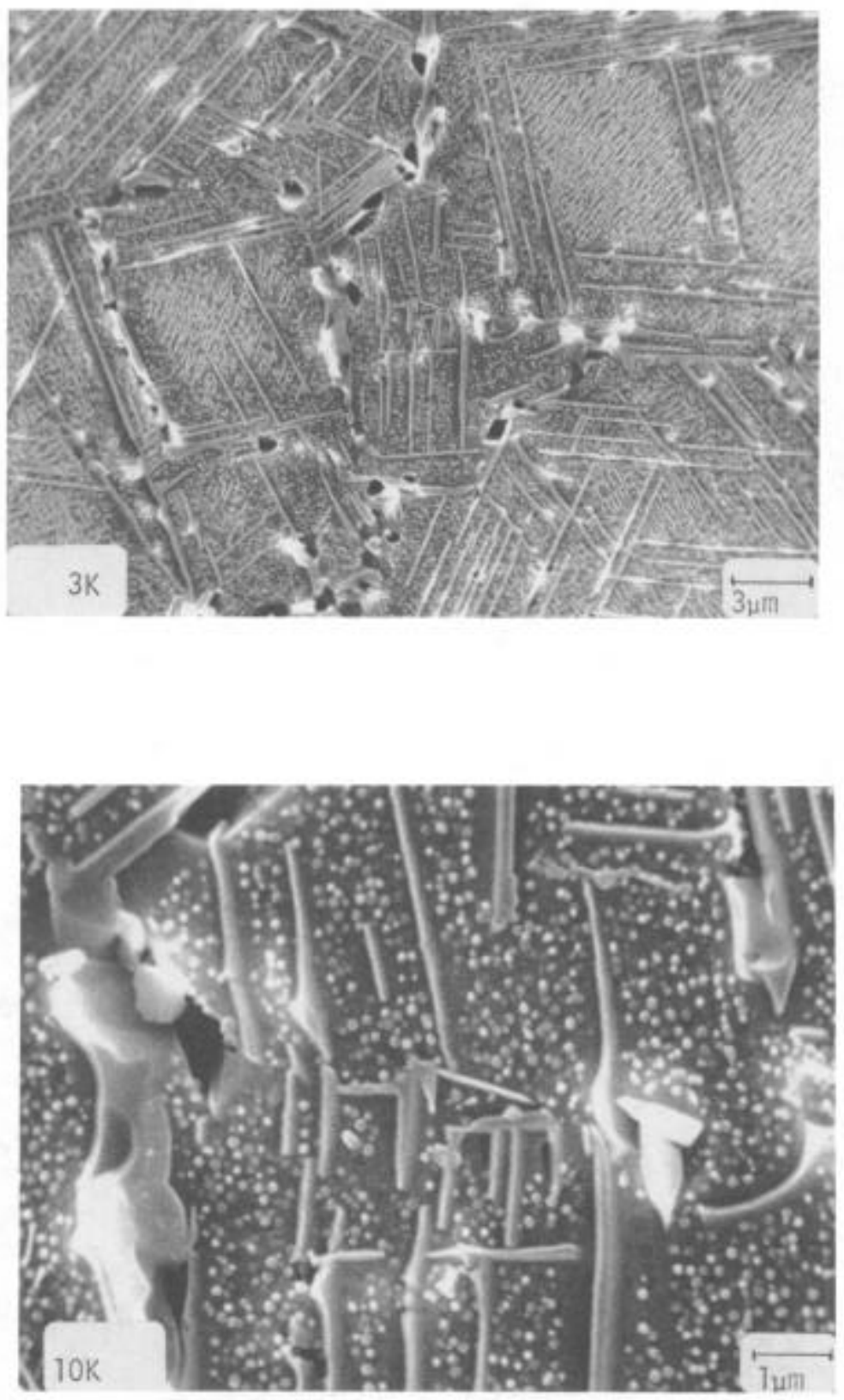

Fig. 8. $28,000 \mathrm{hr}$. Disk T-5. 

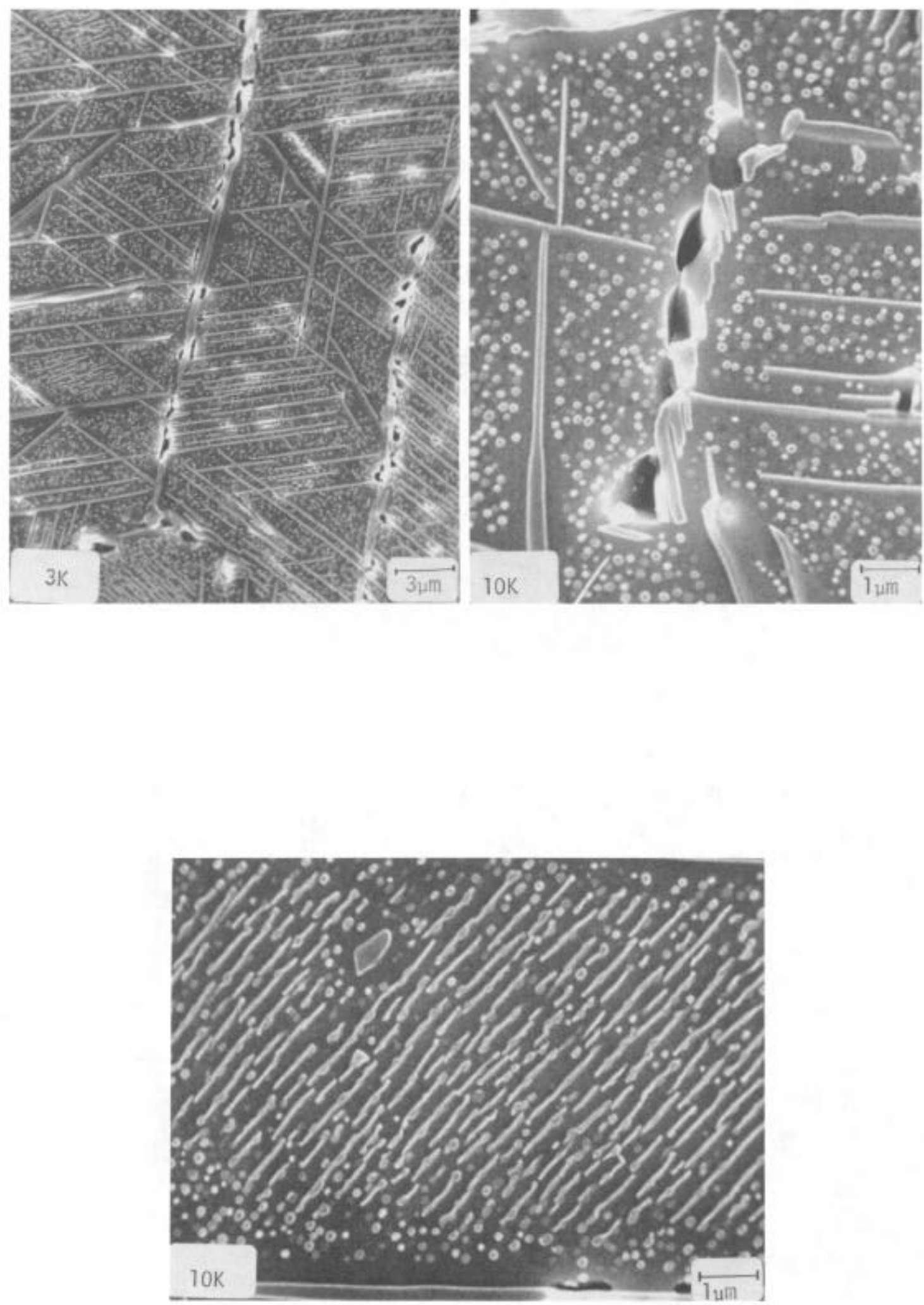

Fig. 9. $28,000 \mathrm{hr}$. Disk Top. 


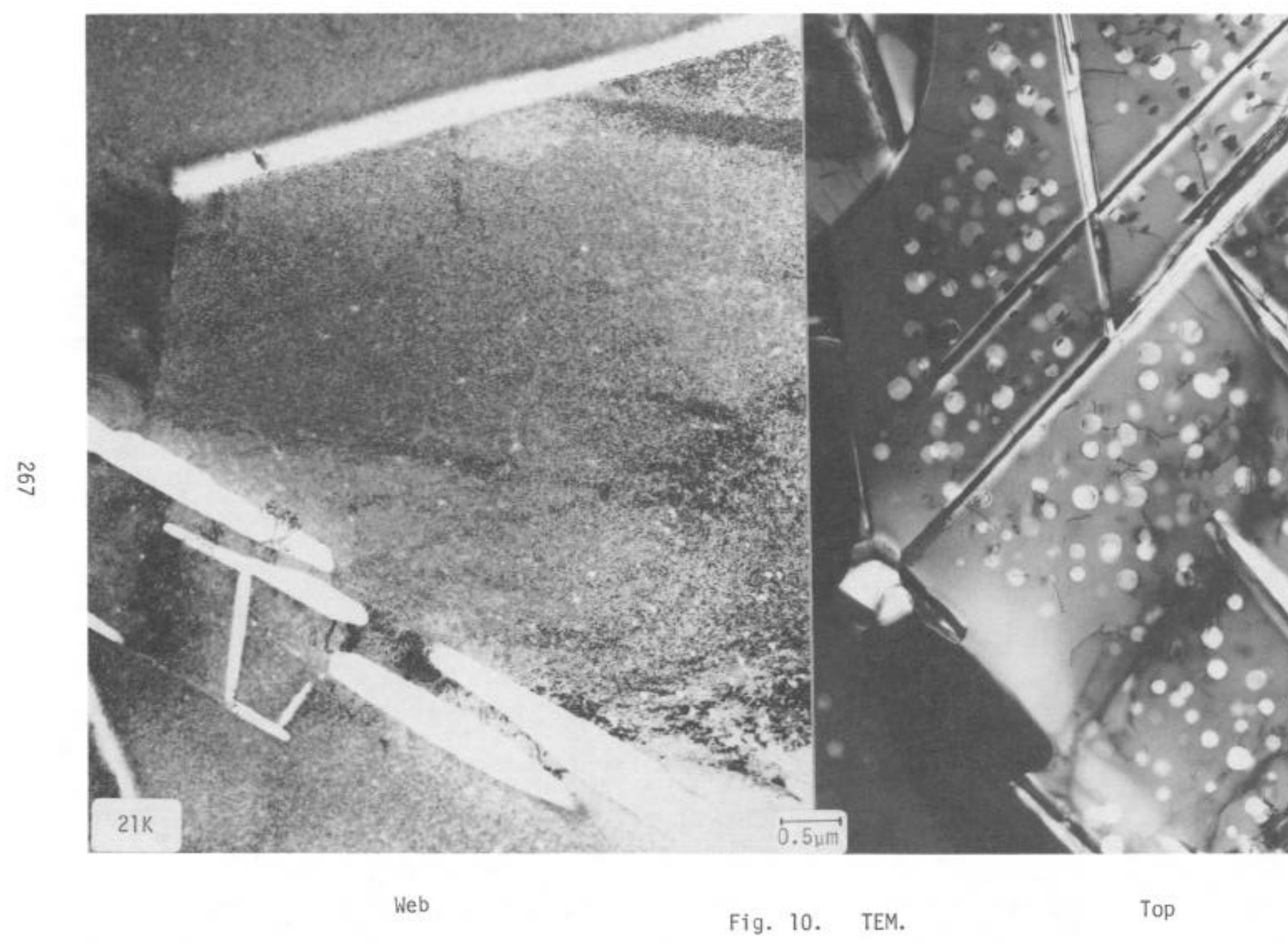




\section{Conclusions}

From a comparison of the structures developed at the various S/R test temperatures of the GE study, the following conclusions are drawn from the structures found in the 28,000 hour disk study:

1. The top of the firtree may have been as high as $1325^{\circ} \mathrm{F}$.

2. The base of the firtree appears to have been exposed to $1100^{\circ} \mathrm{F}$.

3. $\alpha \mathrm{Cr}$ begins to form as low as $1100^{\circ} \mathrm{F}$ in longtimes and grows to as more delta plates form at higher temperatures.

4. In longtime exposures at $1200^{\circ} \mathrm{F}$ and above, the $\gamma$ and delta phases grow at the expense of the $\gamma^{\prime \prime}$ phase.

5. The terminal phase in alloy 718 is the delta phase. 